\title{
Gender, Sexuality, and Bullying Special Issue Editorial
}

\section{Debbie Ging ${ }^{1} \cdot$ Aoife Neary ${ }^{2}$}

Published online: 13 November 2019

(C) Springer Nature Switzerland AG 2019
It is widely accepted that bullying cannot be understood outside of the social and cultural milieu in which it occurs. Yet, in most contexts, the infrastructure of bullying and anti-bullying is more heavily informed by individualised, behavioural, and developmental psychologies that give scant attention to the complex social and intersectional factors at work. To the extent that such conceptualisations of bullying consider gender and sexuality, they tend to emphasise gender and sexuality difference, often in bio-essentialising terms. For example, some bullying narratives (re)produce the notion that boys are more direct, while girls are more likely to engage in mean or indirect bullying (Ringrose 2006). Such reductive discourses are not only reproductive of gender stereotypes, they also fail to acknowledge the spectrum of gender and sexuality diversity, intersectional identities, and the myriad social and cultural factors upon which gender- and sexuality-based bullying is predicated. Several scholars note the tendency of anti-bullying discourses to constitute individuals through discourses of victimisation and protection (Bryan and Mayock 2012, 2017) whilst reproducing what Ringrose and Renold (2010) call 'normative cruelties' of masculinity and femininity - everyday, normative practices that are inextricably connected to violence but are glossed over by anti-bullying frameworks. In this light, it is not surprising that many scholars of gender and sexuality suggest that the bullying/anti-bullying discourse, as it exists, is not fit for purpose (Ringrose and Renold 2010; Ringrose 2008; Formby 2015; Payne and Smith 2013; Rawlings 2016).

In recent years, a growing body of literature has been stretching the ways that we might think about and approach gender- and sexuality-based bullying. Through such work, we are invited to think outside individualised framings of the

Debbie Ging

debbie.ging@dcu.ie

$\triangle$ Aoife Neary

aoife.neary@ul.ie

1 School of Communications, Dublin City University, Dublin, Ireland

2 School of Education, University of Limerick, Limerick, Ireland bullying/victim binary to inquire into the normalised processes of gender and sexuality socialisation, how they enable gender- and sexuality-based bullying with differential, intersectional effects (Payne and Smith 2013; Ringrose and Renold 2010; Pascoe 2011). We are provoked to think 'beyond bullying', as the Beyond Bullying Project ${ }^{1}$ does, to inquire into the complex, ordinary stories that interventionist bullying frameworks might obscure (Gilbert et al. 2018). We are also encouraged to engage with the messiness of this terrain; to notice how we are all implicated in bullying and how, while accountability and responsibility matter, they "cannot be located in a specific individual, nor a specific event, place or time...neither are they virtues, straightforward or easily apprehended (Rasmussen et al. 2017).

Following these lines of thinking, we are drawn to ask critical questions like: In what ways does the 'problem' of genderand sexuality-based bullying take shape across contexts? What kinds of approaches and 'solutions' to gender- and sexualitybased bullying are necessitated by this conceptualisation of bullying? What are the discursive and material effects of such conceptualisations and responses? Evidently, much research has already been addressing these questions and this special issue was motivated by a desire to contribute to this critical discussion, opening up an opportunity to bring together scholarly work on gender- and sexuality-based bullying that is informed by a variety of disciplinary and conceptual frameworks, united by an interest in the questions above. We believe that such critical perspectives, ones that grapple with the messy architecture of bullying, are all the more urgent at a time in which bullying-whether misogynistic, homophobic, transphobic, racist, xenophobic, classist, or ablist-has become a mainstream political strategy among world leaders and a key rhetorical tactic in the culture wars online.

In most contexts, the intention to protect victims of bullying, punish perpetrators of bullying, and prevent future bullying drives a comprehensive infrastructure of anti-bullying policy, strategy, and practice. While such efforts attempt to respond to and address incidents of gender- and sexuality-based bullying,

\footnotetext{
${ }^{1} \mathrm{https} / /$ beyondbullyingproject.com/
} 
they can leave the institutionalisation of gender and sexuality normativity intact. For example, in primary school contexts, those charged with the prevention of homophobic and transphobic bullying are often very comfortable with enacting specific anti-bullying procedures, but are much less willing to engage with, educate about, or interrogate gender and sexuality normativity (Neary et al. 2016). Reductive discourses of childhood innocence and age-appropriateness circulate and mingle with national imaginaries of progressivism (Neary and Rasmussen 2019) and neoliberal logics of competitiveness, making it much easier to frame diversity and difference within an anti-bullying than a critical education model. Indeed, the bullying framework is often the only manner through which children and young people hear about LGBTQI+ identities in schooling contexts (Gilbert 2014). But, of course, children and young people are influenced too by family, peer groups, internet, and social media networks. Thus, anti-bullying policies and interventions which treat school and peer group environments as hermetically sealed spaces are unlikely to succeed, as they are not cognisant of and do not respond to the broader power dynamics and social structures which give rise to these patterns of behaviour in the first place. In this special issue, Vina Adriany's paper "II don't want to play with the Barbie boy": Understanding gender-based bullying in a kindergarten in Indonesia' highlights the gendered conditions through which play is structured and experienced in early childhood education. Adriany's paper offers us a glimpse into the minutiae of gendered relations in early childhood, animating in the Indonesian context some of the normalised, taken-for-granted practices in early socialisation that are so powerfully productive in the development and policing of gender and sexuality norms (Renold 2005; Robinson 2005; Blaise 2012).

The development of gender- and sexuality-based bullying policies is widely understood as a crucial starting point for acknowledging, dealing with, and preventing bullying on these grounds. However, much recent research has highlighted the ambivalent effects of such policy-making. For example, Bailey (2017) explores how anti-bullying policies are constrained within the complex relationship between church and state in Irish primary schooling, pointing out that the gap between the rhetoric of policy and its enactment in practice. In this special issue, Elizabeth Payne and Melissa Smith make a new contribution to this conversation as they drill down into the legislation-policy-practice nexus. Their paper provides much-needed insight into the challenges facing policymakers and LGBTQI+ advocates in navigating bureaucratic regimes that are deeply politically cautious. Despite best efforts to ensure that education policy arising from equality legislation addresses the systemic social conditions that enable bullying, attempts to avoid controversy or be seen as overly 'political' result in a return to traditional, individualising surveillance, and monitoring approaches to bullying. Furthermore, this paper reminds us that the policing and silencing of LGBTQI+ youth can actually be enabled by anti-bullying policy that appears as 'neutral'.

Audrey Bryan's paper in this special issue also intervenes in this domain. Her critical discourse analysis of anti-bullying strategies and policies in Ireland interrupts the problematic and reductive risk and mental health discourses that circulate in the anti-bullying terrain of education. It makes a rich and valuable contribution in its teasing out of the fine-grained ways that such discourses can appear as monocausal and actually play their part in restigmatizing and constituting LGBTQI+ youth as deficit, highlighting how the emphasis on bullying can detract from the 'mundane, everyday school-based features and practices which create the conditions whereby bullying can flourish'. This paper provides a robust argument for the need to attend to complexity and nuance in anti-bullying responses.

Recent critical thinking on gender- and sexuality-based bullying has taken care to remind of the necessity to consistently acknowledge how the individual and the social are linked. The oft-mentioned topic of 'toxic masculinity' is an obvious case in point here, whereby both physical and verbal violence is wielded, not solely to overpower other boys for personal gain but ultimately to maintain patriarchal control over women, non-normative boys, people of colour, and anyone else who threatens to disrupt hegemonic masculinity. The current drive in the USA to construct mass shootings as individual 'mental-health issues', despite evidence that the common thread identified among perpetrators is a history of domestic violence, should warn us to the dangers of attributing individual motives to behaviours that have complex social roots.

This recognition of the personal dynamics of bullying as inextricably bound up with its wider political operations may help us to forge stronger epistemological and methodological links with those working in areas such as hate speech and social media studies. The assumption that hate and abuse are individual acts or that they are always enacted in anger overlooks the fact that hate is deliberately and strategically used for political ends, whether keeping women in positions of subordination, maintaining white supremacy, or securing the heteronormative status quo. In addition to this, the circulation of hate both offline and online is carefully managed both by political groups and by social media platforms, for whom hate's 'affective intensity' (Paasonen 2015) has both political and economic value. The non-consensual sharing of intimate images, for example, commonly referred to as 'revenge porn', is frequently used by men as means of shaming women and keeping them in their place in the context of a 'sexual marketplace' that is still dominated by double standards. The shared image has potential social, economic, and political value not only for the sharer, but also for his peer group, for antifeminist assemblages, for porn sites, and for the social media platforms on which the image is shared. However, within the 
protectionist discourse of 'sexting' which characterises most anti-bullying policy, non-consensual image sharing becomes framed as an interpersonal act entailing individual risk and responsibility. To the extent that it recognises gender dynamics, it is usually to place responsibility and blame on the female rather than on the person who has violated her digital rights. This individualist framework fails to capture either the gender relations of the wider peer group or the political economy of sexualised images on women online.

Emily Setty's article in this special issue makes an important contribution in this regard, by attending to the peer contexts in which sexting can occur. This extends commonsense understandings of sexting as a transgressive individual act to a set of cultural practices, in which bystanders play a significant role. Setty shifts the framing of this issue away from protectionist discourses toward a language of digital rights. Her work provides rich new insight into young people's experiences of the largely normalised practice of sexting, interrupting, and destabilising reductive constructions of this practice and the youth who engage in it. By exploring how the practice of sexting animates and amplifies the power dynamics of gender and sexuality that exist in young people's lives, Setty reveals a tendency towards denial of rights to bodily and sexual expression for young women in particular. She advocates for 'a collectivist digital sexual ethics based upon both rights to one's body and freedom from harm'.

To move beyond infrastructures of bullying and antibullying that have problematic effects is not to advocate for, or predict in advance, one ideal conceptualisation, model, or approach (Talburt and Rasmussen 2010). We believe it is crucial to maintain openness to a spectrum of theories and methodologies that can travel across domains, disciplines, and topics in generative ways (Rasmussen and Allen 2014), thus helping to grapple with the messiness of the conditions in which bullying, harassment, and discrimination emerge. Indeed, in recent times, post-humanist/more-than-human, new materialist thinking, and methods that supply 'a more nuanced view of the micropolitics' (Fox and Alldred 2016) have been put to work in alluring and generative ways to rethink the bullying/anti-bullying terrain (see for example Ringrose and Rawlings 2015; Huuki and Renold 2016; Renold and Ringrose 2017).

In this vein, drawing on affect theory, Kim Sylwander's paper in this special issue explores the affective flows of online assemblages, highlighting how such thinking casts a new light for interrogating the complexity of gender and sexualised hate and its circulation in a multiplicity of forms. Importantly, Sylwander's work refuses to posit technology as a force beyond social determinism, yet is also attentive to how the technological affordances of different online spaces enable communicative flow and particular atmospheres of hate and misogyny. Expanding materialities beyond technology to include also bodies and clothing, she explores how these factors shape the affective relationality of digital atmospheres. Sylwander's attention to the notion of affective atmospheres and her focus on school climates resonates well with Sharon L. Bruner et al.'s concept of an 'interdisciplinary ecological framework'. In their paper, Bruner et al. set forth the potential of an interdisciplinary ecological theory for making sense of LGBT violence in schools but are careful to assert a reimagining of concepts such as 'resilience' that are so often talked about and approached in individualising terms in bullying discourses. They comprehensively develop a framework which has the potential to interrupt the more systemic, institutionalised aspects of LGBT violence and attend to the complex, material effects of intersectional identities.

Taken together, the contributions to this special issue point strongly to the need for systemic and structural understandings of and responses to gender- and sexuality-based bullying. Both critical media literacy and rights-based sex education are essential, therefore, to advancing a better understanding of bullying as a strategy of social power dynamics - indeed as a mechanism for maintaining the status quo - as well as the manifestation of individual psychological problems. This is not to disregard psychological perspectives but rather to encourage transdisciplinary and holistic approaches that situate individual and interpersonal psychologies in the complex socio-economic, political, and cultural constellations from which they emerge and which they must navigate.

However, more holistic and integrated approaches to gendered and sexual bullying face substantial challenges in light of the growing trend toward neoliberal policy-making (Meyer 2016). While neoliberal capitalism is primarily involved with advancing the interests of large corporations, it is also heavily invested in diminishing the social safety net (Hilgers 2013). A key part of this strategy is to responsibilise individuals for their own health and psychological wellbeing, hence the increasing tendency to favour psychological, genetic, and neuroscientific studies over the type of sociological or political economic research which holds economic systems and state policy accountable for social problems such as poverty, homelessness, psychological disorders, violence, and - by extension—bullying. As Holmer Nadesan (2002: 403) asserts, 'More recently, the public has been bombarded with a 'scientific' discourse that implies a bio-genetic essentialism through its explication of phenomena such as intelligence, sexuality and aggression as neural-biological outcomes of genetic factors affected by natural selection'.

Research which shows that phenomena can be located in individual bodies or minds is attractive because it supports solutions that operate at the level of individual behaviour (Ging 2009). According to Sims-Schouten and Edwards (2016), the current understandings of resilience that characterise most anti-bullying interventions emphasise individual responsibility and adaptability. Drawing on Bauman (2000), they argue that this neoliberal framework proposes that human 
wellbeing is best understood through the maximisation of entrepreneurial freedoms within an institutional structure. For Sims-Schouten and Edwards (2016), 'the political ideal of individual freedom and choice that lies at the heart of this, is being reproduced in the classroom and social lives of the young people'. However, they also contend that, while notions of collective responsibility have been replaced by notions of self-responsibility, young people do not have adequate tools for the task, concluding that 'individualisation is a fate not a choice' (Bauman 2000). An awareness of the systemic and institutional nature of gender and sexual-based bullying is vital, therefore, not only in informing the frameworks that anti-bullying researchers use, but also in giving serious consideration to the wider agendas that this research might be serving. We hope this special issue might encourage researchers working in this field to view gender and sexualbased bullying through such a meta-political lens.

\section{References}

Bailey, S. (2017). From invisibility to visibility: a policy archaeology of the introduction of anti-transphobic and anti-homophobic bullying guidelines into the Irish primary education system. Irish Educational Studies, 36(1), 25-42.

Bauman, Z. (2000). Liquid modernity. Cambridge: Polity Press.

Blaise, M. (2012). Playing it straight: uncovering gender discourse in the early childhood classroom. New York: Routledge.

Bryan, A., \& Mayock, P. (2012). Speaking back to dominant constructions of LGBT Lives: Complexifying 'at riskness' for self-harm and suicidality among lesbian, gay, bisexual and transgender youth. Irish journal of anthropology, 15(2), 8-15.

Bryan, A., \& Mayock, P. (2017). Supporting LGBT lives? Complicating the suicide consensus in LGBT mental health research. Sexualities, 20(1-2), 65-85.

Formby, E. (2015). Limitations of focussing on homophobic, biphobic and transphobic 'bullying'to understand and address LGBT young people's experiences within and beyond school. Sex Education, 15(6), 626-640.

Fox, N. J., \& Alldred, P. (2016). Sociology and the new materialism: theory, research, action. London: Sage.

Gilbert, J. (2014). Sexuality in school: the limits of education. U of Minnesota Press.

Gilbert, J., Fields, J., Mamo, L., \& Lesko, N. (2018). Intimate possibilities: the beyond bullying project and stories of LGBTQ sexuality and gender in US schools. Harvard Educational Review, 88(2), $163-183$.

Ging, D. "All-consuming images: new gender formations in post-CelticTiger Ireland." (2009).

Hilgers, M. (2013). Embodying neoliberalism: thoughts and responses to critics. Social Anthropology, 21(1), 75-89.

Huuki, T., \& Renold, E. (2016). Crush: mapping historical, material and affective force relations in young children's hetero-sexual playground play. Discourse: Studies in the Cultural Politics of Education, 37(5), 754-769.
Meyer, D. (2016). The gentle neoliberalism of modern anti-bullying texts: surveillance, intervention, and bystanders in contemporary bullying discourse. Sexuality Research \& Social Policy, 13(4), 356-370.

Nadesan, M. H. (2002). Engineering the entrepreneurial infant: brain science, infant development toys, and governmentality. Cultural Studies, 16(3), 401-432.

Neary, A., \& Rasmussen, M. L. (2019). Marriage equality time: entanglements of sexual progress and childhood innocence in Irish primary schools. Sexualities, 1363460719861819.

Neary, A., Irwin-Gowran, S., \& McEvoy, E. (2016). Exploring homophobia and transhobia in primary schools. Limerick: University of Limerick, Irish Research Council and Gay and Lesbian Equality Network.

Paasonen, S. (2015). A midsummer's bonfire: affective intensities of online debate. In Hillis, K., Paasonen, S., \& Petit, M. (Eds.) Networked affect, MITPress. 27-42.

Pascoe, C. J. (2011). Dude, you're a fag: masculinity and sexuality in high school. Univ of California Press.

Payne, E., \& Smith, M. (2013). LGBTQ kids, school safety, and missing the big picture: How the dominant bullying discourse prevents school professionals from thinking about systemic marginalization or... why we need to rethink LGBTQ bullying. QED: A Journal in GLBTQ Worldmaking, 1-36.

Rasmussen, M. L., \& Allen, L. (2014). What can a concept do? Rethinking education's queer assemblages. Discourse: Studies in the Cultural Politics of Education, 35(3), 433-443.

Rasmussen, M. L., Sanjakdar, F., Allen, L., Quinlivan, K., \& Bromdal, A. (2017). Homophobia, transphobia, young people and the question of responsibility. Discourse: Studies in the cultural politics of education, 38(1), 30-42.

Rawlings, V. (2016). Gender regulation, violence and social hierarchies in school:'sluts', 'gays' and 'scrubs'. Springer.

Renold, E. (2005). Girls, boys, and junior sexualities. New York: Routledge.

Renold, E., \& Ringrose, J. (2017). Selfies, relfies and phallic tagging: posthuman part-icipations in teen digital sexuality assemblages. Educational Philosophy and Theory, 49(11), 1066-1079.

Ringrose, J. (2006). A new universal mean girl: examining the discursive construction and social regulation of a new feminine pathology. Feminism \& Psychology, 16(4), 405-424.

Ringrose, J. (2008). 'Just be friends': exposing the limits of educational bully discourses for understanding teen girls' heterosexualized friendships and conflicts. British Journal of Sociology of Education, 29(5), 509-522.

Ringrose, J., \& Rawlings, V. (2015). Posthuman performativity, gender and 'school bullying': exploring the material-discursive intra-actions of skirts, hair, sluts, and poofs. Confero: Essays on Education, Philosophy and Politics, 3(2), 1-37.

Ringrose, J., \& Renold, E. (2010). Normative cruelties and gender deviants: the performative effects of bully discourses for girls and boys in school. British Educational Research Journal, 36(4), 573-596.

Robinson, K. (2005). Doing anti-homophobia and anti-heterosexism in early childhood education: moving beyond the immobilising impacts of 'risks','fears' and 'silences'. Can we afford not to? Contemporary Issues in Early Childhood, 6(2), 175-188.

Sims-Schouten, W., \& Edwards, S. (2016). 'Man up!'bullying and resilience within a neoliberal framework. Journal of Youth Studies, 19(10), 1382-1400.

Talburt, S., \& Rasmussen, M. L. (2010). 'After-queer' tendencies in queer research. International Journal of Qualitative Studies in Education, 23(1), 1-14. 